\title{
SPONTANEOUS CONSOLIDATION OF SCAPHOID NONUNION IN A CHILD
}

\author{
Pavel Manak ${ }^{\mathrm{a}}$, Pavel Drac ${ }^{\mathrm{a} *}$, Boris Paucek ${ }^{\mathrm{b}}$ \\ a Department of Traumatology, University Hospital, Olomouc, Czech Republic \\ ${ }^{b}$ Clinic of Radiology, Teaching Hospital, Olomouc \\ e-mail:dracpa@seznam.cz
}

Received: July 23, 2008; Accepted: October 24, 2008

Key words: Childhood scaphoid nonunion/Spontaneous consolidation/Conservative treatment/Computed tomography

Background: Scaphoid nonunion is very rare in childhood.

Case report: A 14 year old boy with scaphoid nonunion confirmed with CT did not past scheduled surgery. In spite of the short period of immobilisation union occurred and two years after the injury he was completely asymptomatic.

Conclusions: We suspect that injury to the scaphoid, in this case may have accelerated the union shortly before the end of ossification.

\section{INTRODUCTION}

Fracture of the scaphoid bone is one of the least common fractures in childhood and scaphoid nonunion is very rare, according to a number of publications ${ }^{1-4}$. Wulff and Schmidt ${ }^{5}$ found in the world literature to 1998 , childhood scaphoid nonunion described only 19 times and Fabre et al. ${ }^{6}$ to 2001 , altogether 29 times. This generally accepted notion is countered by Toh et al. ${ }^{7}$ who described type D2 scaphoid nonunions (according to Herbert's classification) in 32 out of 64 children treated for injury to the scaphoid bone in the period between 1984-1999. A majority of authors ${ }^{1-4,8-18}$ recommend surgery for nonunion of the scaphoid in children as the treatment of choice. We found only two cases in the literature of nonunion of the scaphoid in children aged eight and half and ten years, treated conservatively ${ }^{6,19}$. The spontaneous consolidation of the scaphoid nonunion we describe here has not been published before.

\section{CASE REPORT}

In 2004 on $25^{\text {th }}$ April a 14 year old boy fell on the sports ground and the following day was investigated by the Department of Traumatology, Faculty Hospital in Olomouc for pain in the right wrist. Examination revealed swelling of the radial part of the wrist with tenderness in the anatomical snuff box. From the X-ray, comminuted fracture of the right scaphoid bone was assessed. CT examination in longitudinal scans of $1 \mathrm{~mm}$ however, showed scaphoid nonunion (see Fig. 1). There was cyst formation at the fracture site and the scaphoid was split into three fragments with distinct sclerosis of the broken parts. The child's mother revealed that two years previously the boy had fallen from his bike and from that time repeatedly complained of intermittent pain in the right wrist. A record of this injury was however not available. Due to the tenderness, a short arm plaster cast under the elbow with immobilisation of the thumb was applied and we recommended an operation. The mother agreed to the operation but requested that it be postponed. On $15^{\text {th }}$ June 2004 the splint was removed and a removable splint was used because of the subsiding pain. On the request of the mother the date for the operation was changed several times and finally set for $29^{\text {th }}$ September 2004. The wrist

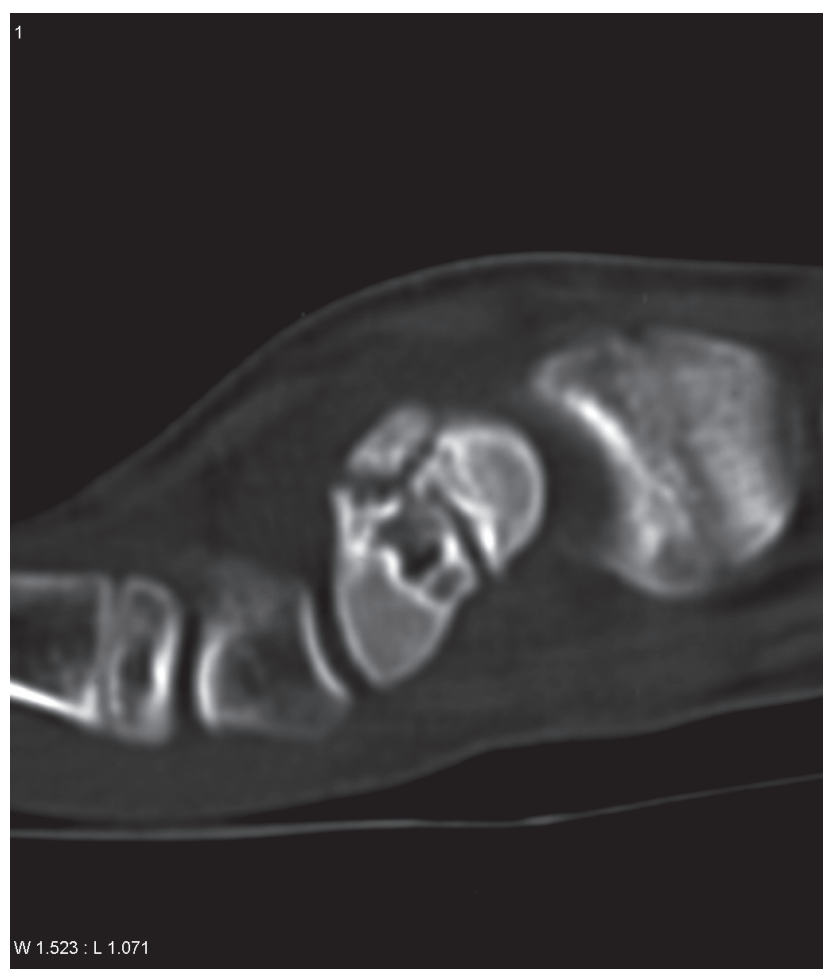

Fig. 1. CT examination of right scaphoid. May 2004. A series of $1 \mathrm{~mm}$ CT scans shows expanded image of right scaphoid. Fracture gap is wide, there is sclerosis in fracture region with formation of pseudocyst. 

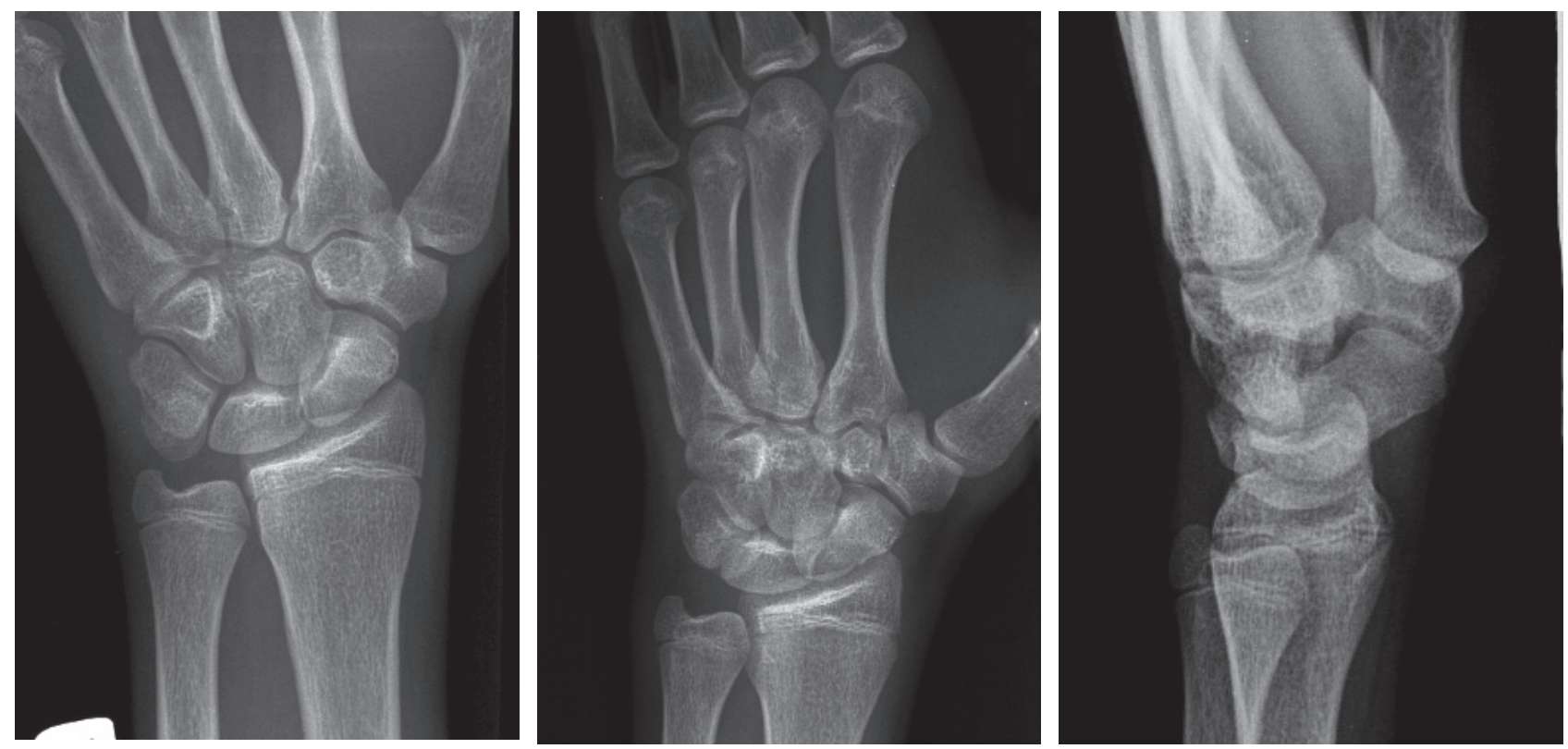

Fig. 2a, 2b, 2c. X-ray of right wrist. September 2006. Normal appearance of right scaphoid with evidence of consolidation of original scaphoid nonunion.

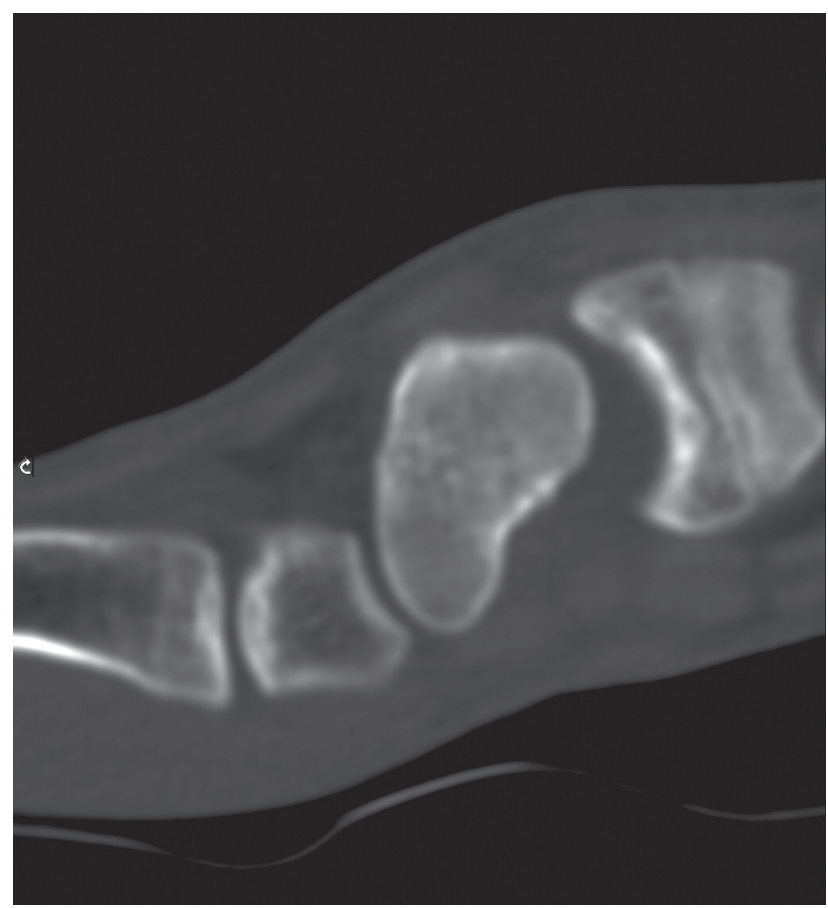

Fig. 3. CT scan of right scaphoid. October 2006. A series of $1 \mathrm{~mm}$ CT scans shows complete consolidation of scaphoid structures in area of originally diagnosed nonunion. The scaphoid cortex is continuous and scaphoid bone is completely healed.

was held without fixation. The boy did not appear for the scheduled admission.

He only came to our department in 2006 , on $26^{\text {th }}$ September, two years after the injury. He was completely asymptomatic, the wrist was pain free during physical examination and range of movement was the same as for the

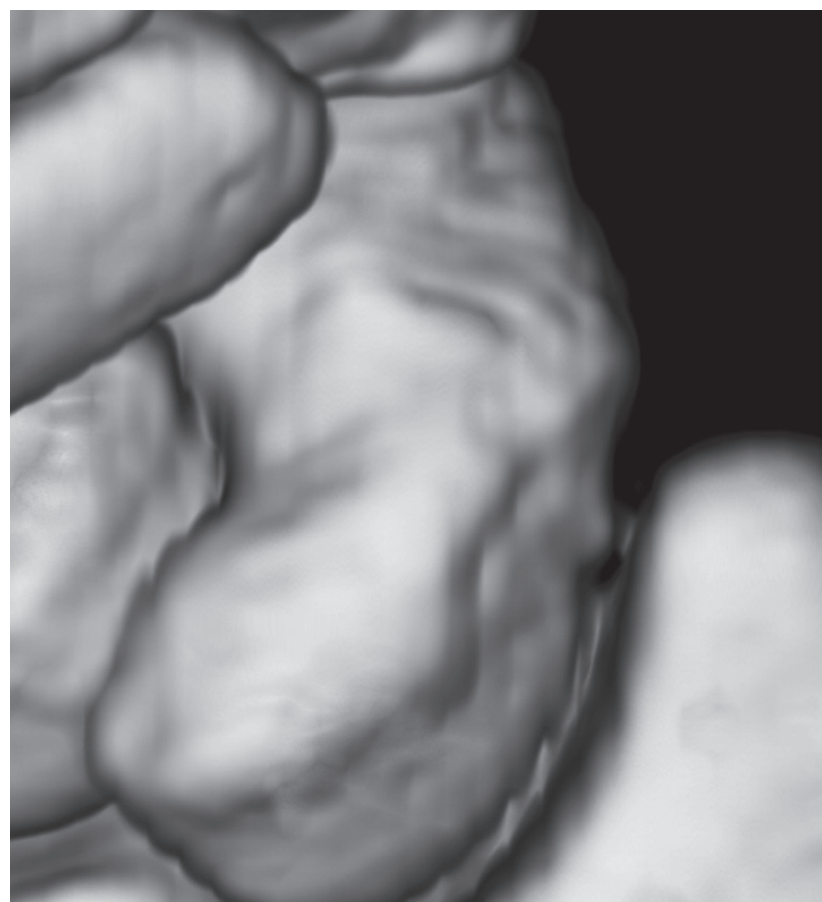

Fig. 4. 3-D reconstruction of $1 \mathrm{~mm}$ CT scans, shows regular structure of scaphoid without any evidence of nonunion. Findings confirm complete consolidation.

uninjured wrist. The check-up X-ray (see figures 2a-c) and CT examination revealed consolidation of the scaphoid nonunion with only residual structural changes (see Figs. 3 and 4). The MRI examination was scheduled but the patient failed to attend. 


\section{DISCUSSION}

Scaphoid nonunions in children are rare and usually follow unrecognised and untreated fractures. In case of early diagnosis and adequate conservative treatment, the incidence of nonunion is $0.8 \%$ (ref. $^{3}$ ). De Boeck et al. ${ }^{19}$ and Fabre et al. ${ }^{6}$ described scaphoid nonunion in an eight and half year old girl and a ten year old boy, respectively. The girl was injured seven months before nonunion was diagnosed. The wrist was immobilised for two months with a long arm cast over the elbow with the thumb included and afterwards for 6 weeks with a short cast under the elbow ${ }^{4}$. The clinical examination one year later showed the nonunion had healed and the child was painfree with full movement. The boy had sustained injury 11 months before the presentation of the nonunion which healed after six weeks immobilisation ${ }^{6}$. On the basis of these experiences, the authors recommended that the nonunion be immobilised for three months after detection. If union is not achieved after that, surgery is indicated.

Scaphoid ossification in boys is complete by year 15 and in girls by year $13.5\left(\right.$ ref. $\left.{ }^{5}\right)$. Suzuki and Herbert ${ }^{20}$ reported spontaneous correction of DISI deformity and remodelling of deformed scaphoid four years after operation in an 11 year old boy.

\section{CONCLUSION}

The nonunion in our patient was detected at the age of 14 years and 4 months and the union occurred in spite of the short period of immobilisation. We suspect that injury to the scaphoid, in this case may have accelerated the union shortly before the end of ossification.

\section{REFERENCES}

1. Caputo AE, Watson HK, Nissen C. Scaphoid nonunion in a child: a case report. J Hand Surg 1995; 20A:243-245.

2. Christodoulou AG, Molton CL. Scaphoid fractures in children. J Pediatric Orthop 1986; 6:37-39.

3. D’Arienzo M. Scaphoid fractures in children. J Hand Surg 2002; 27B:424-426.

4. Goddard N. Carpal fractures in children. Clinical Orthop Rel Res 2005; 432:73-76.

5. Wulff RN, Schmidt TL. Carpal fractures in children. J Pediatric Orthop 1998; 18:462-465.

6. Fabre O, De Boeck H, Haentjens P. Fractures and nonunions of the carpal scaphoid in children. Acta Orthop Belg 2001; 67:121-125.

7. Toh S, Miura H, Arai K, et al. Scaphoid fractures in children: problems and treatment. J Pediatric Orthop 2003; 23:216-221.

8. Duteille F, Dautel G. Non-union fractures of the scaphoid and carpal bones in children: surgical treatment. J Pediatric Orthop 2004; B13:34-38.

9. García-Mata S. Carpal scaphoid fracture nonunion in children. J Pediatric Orthop 2002; 22:448-451.

10. Henderson B, Letts M. Operative treatment of pediatric scaphoid fracture nonunion. J Pediatric Orthop 2003; 23:402-406.

11. Littlefield WG, Friedman RL, Urbaniak JR. Bilateral non-union of the carpal scaphoid in a child. A case report. J Bone Joint Surg 1995; 77A:124-126.

12. Martini AK, Schiltenwolf M. Das Schicksal des Handgelenkes beim spontanen Verlauf der Kahnbeinpseudarthrose. Handchirurgie Mikrochirurgie Plastische Chirirurgie 1995; 27:201-207.

13. Maxted MJ, Owen R. Two cases of nonunion of carpal scaphoid fractures in children. Injury 1982; 13:441-443.

14. Mintzer CM, Waters PM, Simmons BP. Nonunion of the scaphoid in children treated by Herbert screw fixation and bone grafting. $\mathrm{J}$ Bone Joint Surg 1994; 77B:98-100.

15. Mintzer CM, Waters PM. Surgical Treatment of pediatric scaphoid fracture nonunions. J Pediatric Orthop 1999; 19:236-239.

16. Onuba O, Ireland J. Two cases of non-union of fractures of the scaphoid in children. Injury 1983; 15:109-12.

17. Pick RY, Segal D. Carpal scaphoid fracture and nonunion in an eight year old child. J Bone Joint Surg 1983; 65A:1188-1189.

18. Southcott R, Rosman MA. Non-union of carpal scaphoid fractures in children. J Bone Joint Surg 1977; 59B:20-23.

19. De Boeck H, Van Wellen P, Haentjens P. Nonunion of a carpal scaphoid fracture in a child. J Orthop Trauma 1991; 5:370-372.

20. Suzuki K, Herbert TJ. Spontaneous correction of dorsal intercalated segment instability deformity with scaphoid malunion in the skeletally immature. J Hand Surg 1993; 18A:1012-1015. 
